\title{
Improved resistance to ischemia and reperfusion, but impaired protection by ischemic preconditioning in patients with type 1 diabetes mellitus: a pilot study
}

Richard Engbersen ${ }^{1,5}$, Niels P Riksen ${ }^{1,2^{*}}$, Marc J Mol ${ }^{6}$, Bert Bravenboer ${ }^{7}$, Otto C Boerman ${ }^{3}$, Patrick Meijer ${ }^{1,4}$, Wim JG Oyen ${ }^{3}$, Cees Tack' ${ }^{2}$ Gerard A Rongen ${ }^{1,2}$ and Paul Smits ${ }^{1,2}$

\begin{abstract}
Background: In patients with type 1 diabetes mellitus (T1DM), cardiovascular events are more common, and the outcome following a myocardial infarction is worse than in nondiabetic subjects. Ischemic or pharmacological preconditioning are powerful interventions to reduce ischemia reperfusion (IR)-injury. However, animal studies have shown that the presence of T1DM can limit these protective effects. Therefore, we aimed to study the protective effect of ischemic preconditioning in patients with T1DM, and to explore the role of plasma insulin and glucose on this effect. Methods: ${ }^{99 m}$ Technetium-annexin A5 scintigraphy was used to detect IR-injury. IR-injury was induced by unilateral forearm ischemic exercise. At reperfusion, Tc-annexin A5 was administered, and IR-injury was expressed as the percentage difference in radioactivity in the thenar muscle between the experimental and control arm 4 hours after reperfusion. 15 patients with T1DM were compared to 21 nondiabetic controls. The patients were studied twice, with or without ischemic preconditioning (10 minutes of forearm ischemia and reperfusion). Patients were studied in either normoglycemic hyperinsulinemic conditions $(n=8)$ or during hyperglycemic normoinsulinemia $(n=7)$. The controls were studied once either with $(n=8)$ or without $(n=13)$ ischemic preconditioning.
\end{abstract}

Results: Patients with diabetes were less vulnerable to IR-injury than nondiabetic healthy controls $(12.8 \pm 2.4$ and $11.0 \pm 5.1 \%$ versus $27.5 \pm 4.5 \%$ in controls; $p<0.05$ ). The efficacy of ischemic preconditioning to reduce IR-injury, however, was lower in the patients and was even completely abolished during hyperglycemia.

Conclusions: Patients with T1DM are more tolerant to forearm IR than healthy controls in our experimental model. The efficacy of ischemic preconditioning to limit IR-injury, however, is reduced by acute hyperglycemia.

Trial Registration: The study is registered at www.clinicaltrials.gov (NCT00184821)

Keywords: Type 1 diabetes, Ischemia-reperfusion injury, Ischemic preconditioning, Hyperglycemia, Annexin A5

\section{Background}

Type 1 diabetes mellitus (T1DM) substantially increases the risk for ischemic heart disease, including acute myocardial infarction [1]. In addition, the mortality rate in various clinical settings of ischemia-reperfusion (IR) injury, including acute myocardial infarction $[2,3]$, and

\footnotetext{
* Correspondence: N.Riksen@aig.umcn.nl

'Department of Pharmacology-Toxicology, Radboud University Nijmegen Medical Centre, P.O. Box 9101, Nijmegen 6500 HB, The Netherlands

${ }^{2}$ General Internal Medicine, Nijmegen, The Netherlands

Full list of author information is available at the end of the article
}

coronary artery bypass grafting [4,5], is higher in patients with diabetes mellitus, both in type 1 and in type 2 diabetic patients. Also, the incidence of heart failure is increased in patients with T1DM, and is directly associated with the glycated hemoglobin $\mathrm{A}_{1 \mathrm{c}}\left(\mathrm{HbA}_{1 \mathrm{c}}\right)$ concentration [6]. Therefore, novel therapies to reduce IR-injury and improve prognosis in patients with T1DM are urgently needed.

The most powerful intervention to limit myocardial infarct size, other than early coronary reperfusion, is ischemic preconditioning, which is defined as a reduction 
in infarct size by a preceding short period of myocardial ischemia [7]. Based on this principle, alternative cardioprotective strategies have been developed, including remote preconditioning and pharmacological preconditioning [8]. These interventions not only protect the heart against IR injury, but also other tissues including the kidney, the brain, the liver, and skeletal muscle. Unfortunately, it has been shown in animal models of myocardial infarction that various comorbidities, including hypercholesterolemia and diabetes, can limit the efficacy of these cardioprotective interventions [9]. In animal models of T1DM, studies on the effect of ischemic preconditioning on myocardial infarct size have yielded contradicting results [10].

In humans, the impact of T1DM on IR-injury and ischemic preconditioning has never been studied in vivo. Therefore, in the current study, we aimed to answer three research questions: 1) does T1DM affect the tolerance for IR?; 2) does T1DM modulate the protective effect of ischemic preconditioning?; and 3) is the effect of T1DM on these parameters dependent on the plasma glucose and insulin concentrations?

To this end, ${ }^{99 \mathrm{~m}}$ technetium annexin A5 scintigraphy was used as a well-validated model of forearm IR-injury [11-15]. This model is based on the fact that early after reperfusion phosphotidylserin residues are exposed on the outer membrane leaflet of affected cells, as an early marker for cellular damage [16]. Annexin A5 binds with a high affinity to these residues. By labeling recombinant human annexin A5 to ${ }^{99 \mathrm{~m}} \mathrm{Tc}$, these changes can be detected in humans in vivo as a marker for IR-injury.

\section{Materials and methods}

\section{Ethics statement}

The protocol has been approved by the Institutional Review Board of the Radboud University Nijmegen Medical Centre, and the study was performed in compliance with the recommendations of the Declaration of Helsinki. All patients signed for informed consent before participation. The study is registered at www.clinicaltrials.gov (NCT00184821).

\section{Subjects and experimental conditions}

Fifteen male patients (aged $>18$ years) with uncomplicated T1DM (defined as the absence of pancreatic beta cell reserve as reflected by a low plasma C-peptide) participated. Patients with hypertension (supine blood pressure $>140$ / $90 \mathrm{mmHg}$ ), diabetic retinopathy, (micro) albuminuria or cardiovascular disease were excluded. All subjects were studied after an overnight fast and 24 hours of caffeine abstinence.

The patients were randomized to either a normal glucose/high insulin group $(\mathrm{n}=8)$ and high glucose/normal insulin group $(n=7)$. All patients lowered their evening dose of insulin dose by $30 \%$ at the night before the experimental days and skipped the morning dose of insulin to compensate for their fasting state. In eight patients, on the days of the experiments, blood glucose was tightly controlled between 4 and $8 \mathrm{mmol} / \mathrm{l}$ until the start of ischemia, using intravenous insulin when needed. In the remaining 7 patients, blood glucose was kept above $15 \mathrm{mmol} / \mathrm{l}$ at the start of ischemia, using intravenous glucose when needed. After one hour of reperfusion, all patients were allowed to have lunch and to use their normal insulin regimen. The results from these patients were compared with a control group of 21 healthy male subjects, who have been described in a previous study [11].

\section{Experimental protocol}

All patients with T1DM were studied twice in a crossover design, with an interval of at least one week in between the experiments. In random order, each patient was subjected to the ischemic exercise protocol alone or to ischemic preconditioning followed by ischemic exercise. The healthy volunteers were subjected to either ischemic exercise alone $(n=13)$ or to ischemic preconditioning followed by ischemic exercise $(\mathrm{n}=8)$.

In the ischemic exercise protocol, after cannulation of an antecubital vein of the dominant forearm, maximal voluntary contraction was determined in the non-dominant arm with a handgrip dynamometer (Baseline Hydrolic Hand Dynamometer, Fabrication Enterprise Inc., Irvington, New York, USA). Subsequently, the circulation of the nondominant arm was occluded for 10 minutes by inflation of an upper arm cuff to $200 \mathrm{mmHg}$. Simultaneously, the subjects performed rhythmic isometric hand gripping exercise at $50 \%$ of maximal voluntary contraction for 5 seconds every 10 -second period until exhaustion. The total duration of ischemia was 10 minutes. Immediately upon reperfusion, $0.1 \mathrm{mg}$ of hydrazinonicotinamide (HYNIC)derivatized recombinant human annexin A5, radiolabeled with $450 \mathrm{MBq}$ Tc-99 m, was administered intravenously ( $5 \mathrm{mSv}$ ). Both hands were imaged at 4 hours after injection with a gamma camera (Siemens Orbiter, Hoffman Estates, Illinois, USA, equipped with low- energy high resolution collimators) connected to a Hermes Gold image processing system (Nuclear Diagnostics, Stockholm, Sweden) as previously described [11].

In the ischemic preconditioning experiments, the 10 minutes of ischemic exercise were preceded by 10 minutes of forearm ischemia (without concomitant handgripping) and 10 minutes of reperfusion.

\section{Preparation of ${ }^{99 \mathrm{~m}} \mathrm{Tc}-\mathrm{HYNIC}$-annexin $\mathrm{A5}$}

Radiolabeled annexin A5 was freshly prepared before each experiment by adding ${ }^{99 \mathrm{~m}} \mathrm{Tc}$-pertechnetate $(1500 \mathrm{MBq})$ in the presence of stannous tricine to succinimidylhydrazinonicotinamide (HYNIC)-conjugated recombinant human 
annexin A5 (NAS 2020, $0.275 \mathrm{mg}$ per vial; Theseus Imaging Corp). For the patients with diabetes who were studied during hyperglycemia, recombinant human annexin A5 (obtained from Theseus Imaging Corporation) was conjugated with HYNIC in our own laboratory. The radiolabeling procedure of this HYNIC-conjugated annexin A5 was identical to that of NAS 2020.

\section{Analytical procedures}

Plasma caffeine concentrations were determined by use of reversed-phase HPLC with UV detection set at $273 \mathrm{~nm}$ according to Schreiber-Deturmeny and Bruguerolle [17]. Insulin was measured by direct radioimmunoassay (RIA) using an International Standard for human Insulin (NIBSC code 83/500). The intra assay coefficient of variation (CV) was $5.6 \%, 6.6 \%$ and $6.7 \%$ at insulin concentrations of 20.5, 41.5, and $56.8 \mathrm{mE} / \mathrm{L}$ and the inter assay $\mathrm{CVs}$ at these concentrations were 9.8\%, $10.0 \%$ and $13.6 \%$. C-peptide was measured with a Double Antibody kit obtained from DPC (DPC Nederland B.V., Breda, the Netherlands).

\section{Data analysis and statistics}

All the digitized gamma camera images were analyzed offline by the same investigator who was unaware of the experimental conditions (WJGO) using Hermes software (Hermes Gold, Nuclear Diagnostics, Stockholm, Sweden). Fixed-size circular regions of interest (ROI) were drawn over the thenar muscle of both hands. Special care was taken to avoid the major arteries and veins in the ROI. To correct for background activity, the final result was expressed as the percentage difference between the Annexin A5 uptake in the ROIs of the experimental hand and control hand ('targeting').

All results are expressed as mean \pm SEM unless indicated otherwise. Between-group differences were assessed using a one-way ANOVA of variance, followed by unpaired $t$-tests to identify significant contrasts.

In the diabetes patients, the effect of ischemic preconditioning was analysed using a paired t-test. The effect of glycemic control during the experiment on the efficacy of ischemic preconditioning was statistically analyzed using a repeated measures ANOVA with ischemic preconditioning as a within-subject factor and the experimental condition as a between subject factor. Possible confounding by age was explored by determining the effect of the inclusion of age as a covariate in this statistical analysis. A two-sided $\mathrm{p}$ value $<0.05$ was considered to indicate statistical significance (SPSS for Windows, release 12.0.1).

\section{Results}

Baseline characteristics of the study groups are summarized in Table 1. The plasma caffeine concentration was less than $0.5 \mathrm{mg} / \mathrm{l}$ in all subjects, indicating good compliance with caffeine abstinence. The plasma C-peptide concentration was $\leq 0.05 \mathrm{nmol} / \mathrm{l}$ in all diabetic patients, confirming a type 1 diabetes.

\section{Metabolic control during the experiment}

As intended, the two groups of patients with diabetes significantly differed with respect to plasma insulin and glucose concentrations (see Table 1). Remarkably, in the patients who did not receive intravenous insulin treatment prior to ischemic exercise, the plasma insulin concentration did not significantly differ from the levels observed in the healthy volunteers.

The difference in plasma glucose concentration between the normoglycemic and hyperglycemic non-preconditioned diabetes groups persisted throughout the reperfusion period: $6.8 \pm 1.9(\mathrm{SD} ; \mathrm{n}=8)$ versus $16.4 \pm 2.3 \mathrm{mmol} / \mathrm{l}(\mathrm{n}=7)$ at 1 hour and $11.6 \pm 3.5(\mathrm{n}=8)$ versus $19.3 \pm 1.6 \mathrm{mmol} / \mathrm{l}$ $(n=7)$ at four hours after reperfusion for the group with and without extra insulin, respectively $(\mathrm{p}<0.005$ at both time points). After ischemic preconditioning followed by ischemic exercise, similar results were obtained: $6.8 \pm 1.8$ $(\mathrm{n}=8)$ versus $19.0 \pm 4.1 \mathrm{mmol} / \mathrm{l}(\mathrm{n}=7)$ at one hour and $12.5 \pm 1.7(\mathrm{n}=8)$ versus $22.2 \pm 4.1 \mathrm{mmol} / \mathrm{l}(\mathrm{n}=7)$ at four hours after reperfusion ( $\mathrm{p}<0.001$ at both time points).

\section{Annexin A5 targeting after ischemic exercise}

Independent of the metabolic control during the experiment, annexin A5 targeting after ischemic exercise was lower in patients with T1DM than in healthy volunteers $(12.8 \pm 2.4(\mathrm{SEM} ; \mathrm{n}=8)$ and $11.0 \pm 5.1 \%(\mathrm{n}=7)$ in the two groups of patients with diabetes versus $27.5 \pm 4.5 \%$ $(n=13)$ in the healthy controls; $p<0.05$ for diabetes versus control; Figure 1). Ischemic preconditioning tended to reduce targeting in the patients with normal glucose/ high insulin without reaching statistical significance $(12.8 \pm 2.4$ versus $8.4 \pm 1.8 \% ; \mathrm{p}=0.087 ; \mathrm{n}=8)$. In the patients who were studied under hyperglycemic conditions, ischemic preconditioning did not limit targeting (11.0 \pm 5.1 versus $15.9 \pm 7.9 \%$ in absence and presence of ischemic preconditioning, respectively; $\mathrm{p}=0.20$; $\mathrm{n}=7$ ). Within the tested population of patients with diabetes, the protective effect of ischemic preconditioning was significantly higher in those who were studied under normoglycemic hyperinsulinemic conditions as compared with those who were studied during hyperglycemia (repeated measures ANOVA: significant interaction between the effect of ischemic preconditioning and experimental condition $(\mathrm{p}=0.035$ and $\mathrm{p}=0.025$ without and with age as a covariate respectively); Figure 2). In contrast to the patients with diabetes, the healthy volunteers showed a profound and consistent reduction in annexin targeting by ischemic preconditioning (Figure 1). 
Table 1 Baseline characteristics of the subjects

\begin{tabular}{|c|c|c|c|c|}
\hline & T1DM; normal glucose & T1DM; high glucose & $\begin{array}{l}\text { Healthy volunteers } \\
\text { without IP }\end{array}$ & $\begin{array}{l}\text { Healthy volunteers } \\
\text { with IP }\end{array}$ \\
\hline N & 8 & 7 & 13 & 8 \\
\hline Age (years) & $28 \pm 8$ & $35 \pm 11^{*}$ & $22 \pm 3^{*}$ & $24 \pm 4^{*}$ \\
\hline Body mass (kg) & $78 \pm 10$ & $76 \pm 8$ & $74 \pm 9$ & $82 \pm 7$ \\
\hline Height (cm) & $182 \pm 7$ & $178 \pm 4$ & $180 \pm 7$ & $185 \pm 4$ \\
\hline Systolic blood pressure $(\mathrm{mmHg})$ & $129 \pm 9$ & $124 \pm 6$ & $127 \pm 7$ & $131 \pm 7$ \\
\hline Diastolic blood pressure $(\mathrm{mmHg})$ & $78 \pm 5$ & $73 \pm 8$ & $75 \pm 10$ & $66 \pm 10$ \\
\hline Heart Rate (bpm) & $72 \pm 8$ & $65 \pm 6$ & $68 \pm 10$ & $68 \pm 14$ \\
\hline $\mathrm{HbA}_{1 \mathrm{c}}(\%)$ & $7.6 \pm 0.9$ & $8.2 \pm 0.9$ & - & - \\
\hline \multicolumn{5}{|l|}{$\begin{array}{l}\text { Plasma glucose at onset of ischemic } \\
\text { exercise (mmol/l) }\end{array}$} \\
\hline$-\mid P^{*}$ & $6.3 \pm 1.2^{*}$ & $18.2 \pm 1.5^{* *}$ & $4.5 \pm 0.6^{*}$ & \\
\hline$+\mathbb{P}^{*}$ & $6.4 \pm 0.8^{*}$ & $19.4 \pm 2.0^{*}$ & - & $5.0 \pm 1.1^{*}$ \\
\hline \multicolumn{5}{|l|}{$\begin{array}{l}\text { Plasma insuline at onset of ischemic } \\
\text { exercise }(\mathrm{mU} / \mathrm{l})\end{array}$} \\
\hline$-\mid P^{*}$ & $43.9 \pm 27.6^{* *}$ & $10.6 \pm 4.2^{*}$ & $14 \pm 8^{*}$ & - \\
\hline$+\mathbb{P}$ & $28.3 \pm 26.3$ & $9.9 \pm 4.2$ & - & - \\
\hline Maximal voluntary contraction (kg) & $49 \pm 7^{\text {*t }}$ & $40 \pm 6^{*}$ & $42 \pm 9^{+}$ & $62 \pm 12^{*}:$ \\
\hline
\end{tabular}

Values are means \pm SD. ${ }^{*}: p<0.05$ versus healthy controls without IP. ${ }^{+}: p<0.05$ versus healthy controls with IP. ${ }^{*} p<0.05$ versus T1DM with high glucose.

\section{Discussion}

The current study is the first to investigate in humans in vivo whether T1DM affects the tolerance for IR and the protection by ischemic preconditioning. Patients with T1DM appear to be more resistant to IR in the forearm skeletal muscle. The efficacy of ischemic preconditioniong to limit IR-injury, however, is lower in patients with

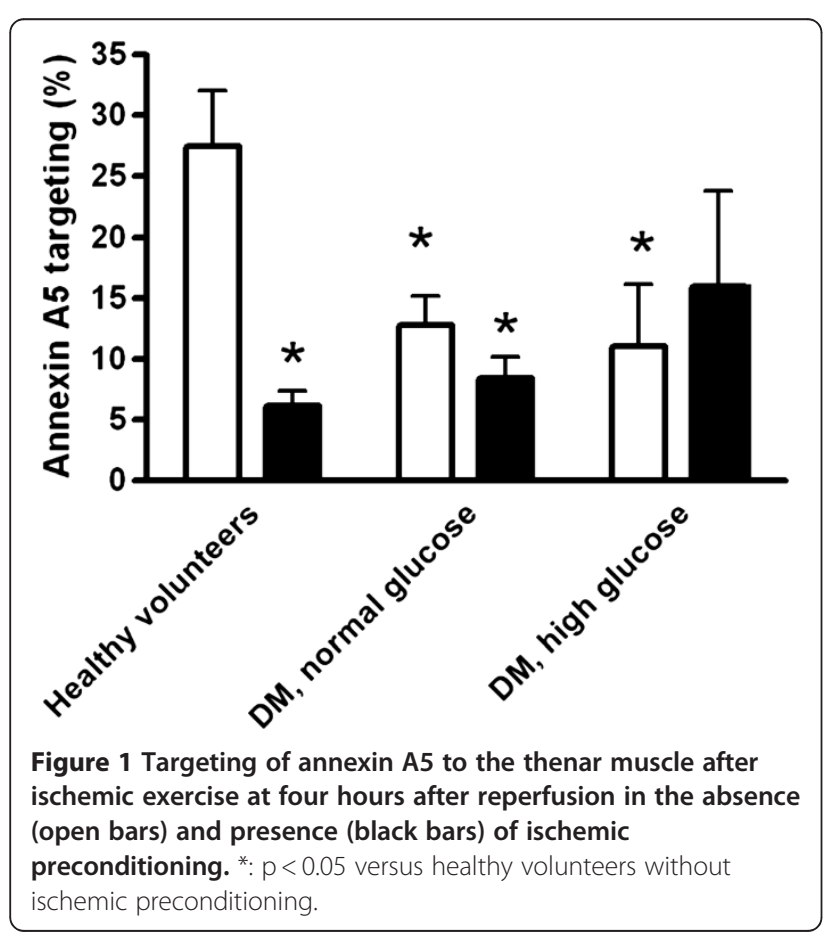

diabetes than in nondiabetic control subjects, and is even completely abolished during hyperglycemia.

Despite optimal reperfusion therapy, morbidity and mortality in patients suffering an acute myocardial infarction remain significant [18]. Therefore, novel strategies to limit IR-injury are warranted. Based on the finding that ischemic preconditioning profoundly reduces myocardial infarct size, several novel treatment modalities have recently been developed and tested in humans, including remote preconditioniong [19], and pharmacological preconditioning [8]. For patients with diabetes, this need for additional treatment is even more urgent, given the fact that the risk of cardiovascular events is

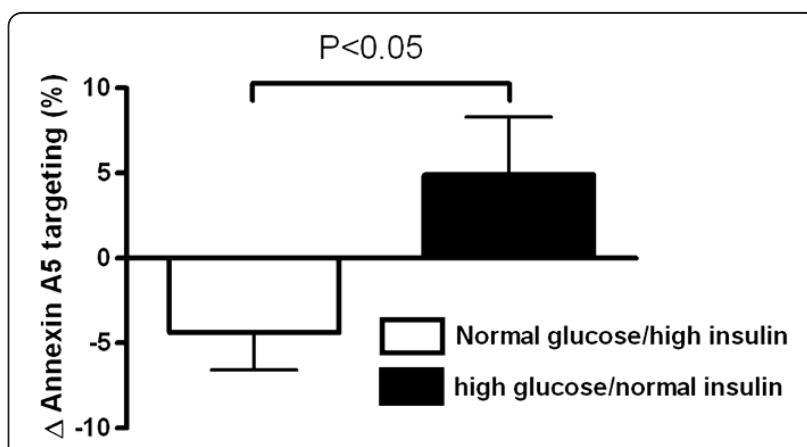

Figure 2 Effect of ischemic preconditioning on annexin A5 targeting in the two experimental conditions in patients with diabetes (normal glucose and high glucose). $\Delta$ targeting was calculated as the targeting after ischemic exercise with preconditioning minus targeting after ischemic exercise without preconditioning. 
higher, and the mortality rate following a cardiovascular event is increased, both in type 1 and in type 2 diabetic patients $[2,3]$. In addition, the incidence of heart failure is higher in patients with T1DM [6]. There are several potential explanations for this worse outcome following infarction in patients with diabetes. In diabetic patients suffering from a myocardial infarction, infarct size (estimated with nuclear imaging) is larger than in nondiabetic patients, both after thrombolysis and after primary percutaneous coronary intervention $[20,21]$. It was suggested, however, that the small difference in infarct size could not completely account for the 4-6 fold increased mortality in the diabetic patients in this study [21]. This was recently confirmed in an animal study, in which the mortality rate following a myocardial infarction was higher in diabetic rats than in control rats, despite similar infarct size. It was speculated that autonomic dysfunction in the diabetic rats contributes to this increased mortality [22].

Despite the clinical observations that suggest that patients with diabetes are more susceptible to myocardial IR-injury, animal studies have provided conflicting results. A vast amount of studies have explored the tolerance of myocardial tissue for IR in animal models of type 1 and type 2 diabetes mellitus [9,10,23-27]. Although some studies have reported that the myocardium is more resistant to IR-injury in animals with T1DM, other studies have found either no effect, or an increased susceptibility. Probably, this tolerance to IR is dependent on the duration of diabetes (an increased resistance has been reported in particular early after the onset of diabetes), the animal species, and the duration of IR [10]. In addition, it has to be taken into account that the animal models of T1DM do not accurately reflect the human pathology of diabetes in all aspects (e.g. the toxins administered to destruct the pancreas might have alternative mechanisms of action, and do not reflect the auto-immune destruction that occurs in humans).

Experiments in animal models of myocardial infarction have demonstrated that comorbidities, including diabetes, myocardial hypertrophy, and hypercholesterolemia can limit the protective effect of (ischemic) preconditioning [9]. Several animal studies have investigated whether the diabetic heart is still amenable to the cardioprotective effect of (ischemic) preconditioning. Most studies in animal models of T1DM (mainly diabetes induced by the administration of streptozotocin) have demonstrated that the cardioprotective effect of ischemic preconditioning is abolished [28,29]. Also, acute hyperglycemia completely abolished the infarct sizelimiting effect of ischemic precondioning [30]. In GotoKakizaki diabetic rats, the cardioprotective effect of preconditioning could be restored, however, by increasing the intensity of the preconditioning stimulus, illustrating that diabetes increases the threshold for preconditioning
[31]. It has been suggested that the diminished potential for cardioprotection in diabetes is due to impaired function of the ATP-dependent potassium channel $\left(\mathrm{K}_{\mathrm{ATP}^{-}}\right.$ channel), or due to decreased phosphorylation of important signalling kinases including Akt and glycogen synthase kinase (GSK)-3 $\beta[10,26]$.

These findings of a reduced efficacy of ischemic preconditioning have been confirmed in experimental studies on IR-injury in human atrial trabeculae: in patients with diabetes, the cardioprotective effect of ischemic preconditioning was either abolished, or the threshold for cardioprotection was increased, possibly due to impaired opening of $\mathrm{K}_{\mathrm{ATP}}$-channels [32-34].

In our study, annexin A5 targeting after forearm IR was lower in patients with T1DM than in nondiabetic control subjects, indicating an increased resistance to IR. We postulate that this is, at least in part, due to the protective effect of insulin against IR-injury. The patients with diabetes and strict administration of insulin during the experiment only marginally differed from healthy controls with respect to the plasma glucose concentration while their plasma insulin concentration was significantly higher. These two groups did not differ at baseline in other respects. Therefore, we propose that the higher circulating insulin contributes to the observed tolerance to forearm IR in this group. This conclusion is supported by a large body of preclinical evidence indicating a protective effect of insulin against IR-induced cell death [35-37]. Based on this preclinical evidence, we expected an increased targeting of annexin A5 after ischemic exercise in the patients with T1DM who were studied during hyperglycemic conditions. This, however, was not observed. We postulate that this is because the protective effect of chronic insulin treatment was still present after skipping one dose of insulin and remained effective during the experiments.

Despite this reduced susceptibility for IR-injury, additional protection by ischemic preconditioning was much less effective in patients with T1DM than in healthy control subjects. In more detail, this protective effect was small, and only observed in patients during normoglycemic conditions. During hyperglycemia, ischemic preconditioning did not reduce annexin A5 targeting at all. In the patients who were studied during hyperglycemia, the plasma insulin concentration did not differ from that observed in healthy volunteers. Therefore, it is unlikely that insulin affected the protective effect of preconditioning in these patients, and it is more likely that the hyperglycemia abolished this protective effect. This is supported by previous preclinical observations in animals using myocardial infarct size as an endpoint $[30,38]$ and it is consistent with epidemiological evidence in humans [39]. A possible explanation for this phenomenon is an acute impairment of mitochondrial $\mathrm{K}_{\mathrm{ATP}}$-channels in response to 
hyperglycemia [38]. The patients who were studied during hyperglycemia were significantly older than the healthy volunteers and the patients who were studied during normoglycemia. Advanced age has been associated with a reduced efficacy of ischemic preconditioning to protect against ischemic cell death [9]. However, the interaction between ischemic preconditioning and experimental condition remained when age was incorporated as a covariate in the analysis of variance, excluding that age is a significant confounder.

Taken together, these data provide human experimental evidence for aggressive normalization of plasma glucose in patients with T1DM who experience repeated bouts of ischemia, such as angina pectoris or transient ischemic attacks, in order to optimize benefit from endogenous protection by ischemic preconditioning. These observations fit well with clinical data suggesting benefit from insulin treatment in critically ill patients with a disturbed tissue perfusion [40].

There are several limitations of our study. Since targeting of annexin A5 after forearm IR was low in patients with diabetes, the potential window of protection by ischemic preconditioning was smaller. This could have affected the power of our study to detect an effect of ischemic preconditioning in these patients. Indeed, in the patients who were studied in normoglycemic conditions, ischemic preconditioning tended to reduce targeting: in 6 out of 8 volunteers targeting was reduced $(\mathrm{p}=0.087)$. Our failure to detect a significant protection by ischemic preconditioning in this group of patients might therefore result from a lack of power due to reduced targeting at baseline. Despite this small window of opportunity to further reduce annexin A5 targeting, in the patients with type 1 diabetes the effect of ischemic preconditioning was significantly affected by the experimental condition (hyperglycemic/normoinsulinemic or normoglycemic/ hyperinsulinemic), consistent with a direct effect of hyperglycemia on the efficacy of ischemic preconditioning to prevent targeting of annexin A5. Secondly, since we did not use a hyperinsulinemic clamp technique, serum glucose levels tended to increase in the normoglycemic group during the last hours of the reperfusion period. Furthermore, our experimental design resulted in differences in both serum glucose and insulin between the two groups of patients with diabetes, complicating the interpretation of the study. However, the current design was chosen to allow an optimal comparison between the healthy volunteers and the normoinsulinemic hyperglycemic patients with diabetes.

\section{Conclusions}

In conclusion, our data indicate that patients with T1DM who are well controlled with chronic insulin treatment appear to be less vulnerable to IR-injury in our experimental model compared to healthy control subjects. Most probably, this is caused by the higher plasma insulin concentration, which induces protection. In addition, hyperglycemia abolishes the protective effect of ischemic preconditioning on IR-injury. Taken together, these findings provide experimental evidence in humans to support aggressive normalization of plasma glucose using insulin in patients with T1DM who experience repeated bouts of ischemia, in order to optimize benefit from insulin-induced protection and endogenous protection by ischemic preconditioning.

\section{Competing interests}

The authors declare that they have no competing interests.

\section{Authors' contributions}

RE participated in the design of the study, carried out the study, performed the analyses, and drafted the manuscript. NPR participated in the analyses of the results, and drafted the manuscript. MJM and BB helped in the patient recruitment and critically reviewed the manuscript. PM participated in performing the experiments. OCB and WJGO performed the analyses of the nuclear studies and critically reviewed the manuscript. PS, GAR, and CT participated in the design of the study and critical review of the manuscript. All authors read and approved the final manuscript.

\section{Acknowledgements}

The authors thank the research staff of the Clinical Research Centre Nijmegen for their assistance in the performance of the experiments. This work was supported by the Dutch Diabetes Foundation. NP Riksen is a recipient of a Clinical Fellowship of the Netherlands Organisation for Health Research and Development (ZonMw) and of a Dekker Fellowship of the Dutch Heart Foundation.

\section{Author details}

${ }^{1}$ Department of Pharmacology-Toxicology, Radboud University Nijmegen Medical Centre, P.O. Box 9101, Nijmegen 6500 HB, The Netherlands. ${ }^{2}$ General Internal Medicine, Nijmegen, The Netherlands. ${ }^{3}$ Nuclear Medicine, Nijmegen, The Netherlands. ${ }^{4}$ Department of Anesthesiology, Radboud University Nijmegen Medical Centre, Nijmegen, The Netherlands. ${ }^{5}$ Slingeland Hospital, Doetinchem, Netherlands. ${ }^{6}$ Canisius Wilhelmina Hospital, Nijmegen, The Netherlands. ${ }^{7}$ Catharina Hospital, Eindhoven, the Netherlands.

Received: 28 August 2012 Accepted: 9 October 2012

Published: 10 October 2012

\section{References}

1. Orchard TJ, Costacou T, Kretowski A, Nesto RW: Type 1 diabetes and coronary artery disease. Diabetes Care 2006, 29:2528-2538.

2. Mathew V, Gersh BJ, Williams BA, Laskey WK, Willerson JT, Tilbury RT, Davis $B R$, Holmes DR Jr: Outcomes in patients with diabetes mellitus undergoing percutaneous coronary intervention in the current era: a report from the Prevention of REStenosis with Tranilast and its Outcomes (PRESTO) trial. Circulation 2004, 109:476-480.

3. Donahoe SM, Stewart GC, MCCabe CH, Mohanavelu S, Murphy SA, Cannon $C P$, Antman EM: Diabetes and mortality following acute coronary syndromes. JAMA 2007, 298:765-775.

4. Thourani VH, Weintraub WS, Stein B, Gebhart SS, Craver JM, Jones EL, Guyton RA: Influence of diabetes mellitus on early and late outcome after coronary artery bypass grafting. Ann Thorac Surg 1999, 67:1045-1052

5. van Straten AH, Soliman Hamad MA, van Zundert AA, Martens EJ, Schonberger JP, ter Woorst JF, de Wolf AM: Diabetes and survival after coronary artery bypass grafting: comparison with an age- and sexmatched population. Eur J Cardiothorac Surg 2010, 37:1068-1074.

6. Lind M, Bounias I, Olsson M, Gudbjornsdottir S, Svensson AM, Rosengren A: Glycaemic control and incidence of heart failure in 20,985 patients with type 1 diabetes: an observational study. Lancet 2011, 378:140-146. 
7. Murry $C E$, Jennings $R B$, Reimer $K A$ : Preconditioning with ischemia: a delay of lethal cell injury in ischemic myocardium. Circulation 1986, 74:1124-1136

8. Riksen NP, Smits P, Rongen GA: Ischaemic preconditioning: from molecular characterization to clinical application. Part II. Neth J Med 2004, 62:409-423.

9. Ferdinandy P, Schulz R, Baxter GF: Interaction of cardiovascular risk factors with myocardial ischemia/reperfusion injury, preconditioning, and postconditioning. Pharmacol Rev 2007, 59:418-458.

10. Whittington HJ, Babu GG, Mocanu MM, Yellon DM, Hausenloy DJ: The diabetic heart: too sweet for its own good? Cardiol Res Pract 2012, 2012:845698.

11. Rongen GA, Oyen WJG, Ramakers BP, Riksen NP, Boerman OC, Steinmetz N, Smits P: Annexin A5 scintigraphy of forearm as a novel in vivo model of skeletal muscle preconditioning in humans. Circulation 2005, 111:173-178.

12. Riksen NP, Zhou Z, Oyen WJ, Jaspers R, Ramakers BP, Brouwer RM, Boerman OC, Steinmetz N, Smits P, Rongen GA: Caffeine prevents protection in two human models of ischemic preconditioning. J Am Coll Cardiol 2006, 48:700-707.

13. Riksen NP, Franke B, Oyen WJ, Borm GF, van den Broek P, Boerman OC, Smits $P$, Rongen GA: Augmented hyperaemia and reduced tissue injury in response to ischaemia in subjects with the $34 \mathrm{C}>\mathrm{T}$ variant of the AMPD1 gene. Eur Heart J 2007, 28:1085-1091.

14. Meijer P, Oyen WJ, Dekker D, Van den Broek PH, Wouters CW, Boerman OC, Scheffer GJ, Smits $P$, Rongen GA: Rosuvastatin increases extracellular adenosine formation in humans in vivo: a new perspective on cardiovascular protection. Arterioscler Thromb Vasc Biol 2009, 29:963-968.

15. Wouters CW, Meijer P, Janssen Cl, Frederix GW, Oyen WJ, Boerman OC, Smits $P$, Rongen GA: Atorvastatin does not affect ischaemia-induced phosphatidylserine exposition in humans in-vivo. J Atheroscler Thromb 2012, 19:285-291.

16. Koopman G, Reutelingsperger CP, Kuijten GA, Keehnen RM, Pals ST, van Oers $\mathrm{MH}$ : Annexin $\mathrm{V}$ for flow cytometric detection of phosphatidylserine expression on B cells undergoing apoptosis. Blood 1994, 84:1415-1420.

17. Schreiber-Deturmeny E, Bruguerolle B: Simultaneous high-performance liquid chromatographic determination of caffeine and theophylline for routine drug monitoring in human plasma. J Chromatogr B Biomed Appl 1996, 677:305-312.

18. Yellon DM, Hausenloy DJ: Myocardial reperfusion injury. N Engl J Med 2007, 357:1121-1135

19. Hausenloy DJ, Mwamure PK, Venugopal V, Harris J, Barnard M, Grundy E, Ashley E, Vichare S, Di SC, Kolvekar S, Hayward M, Keogh B, MacAllister RJ, Yellon DM: Effect of remote ischaemic preconditioning on myocardial injury in patients undergoing coronary artery bypass graft surgery: a randomised controlled trial. Lancet 2007, 370:575-579.

20. Marso SP, Miller T, Rutherford BD, Gibbons RJ, Qureshi M, Kalynych A, Turco M, Schultheiss HP, Mehran R, Krucoff MW, Lansky AJ, Stone GW: Comparison of myocardial reperfusion in patients undergoing percutaneous coronary intervention in ST-segment elevation acute myocardial infarction with versus without diabetes mellitus (from the EMERALD Trial). Am J Cardiol 2007, 100:206-210

21. Alegria JR, Miller TD, Gibbons RJ, Yi QL, Yusuf S: Infarct size, ejection fraction, and mortality in diabetic patients with acute myocardial infarction treated with thrombolytic therapy. Am Heart J 2007, 154:743-750.

22. Rodrigues B, Rosa KT, Medeiros A, Schaan BD, Brum PC, De AK, Irigoyen MC: Hyperglycemia can delay left ventricular dysfunction but not autonomic damage after myocardial infarction in rodents. Cardiovasc Diabetol 2011, 10:26.

23. Paulson DJ: The diabetic heart is more sensitive to ischemic injury. Cardiovasc Res 1997, 34:104-112.

24. Balakumar P, Sharma NK: Healing the diabetic heart: does myocardial preconditioning work? Cell Signal 2012, 24:53-59.

25. Feuvray D, Lopaschuk GD: Controversies on the sensitivity of the diabetic heart to ischemic injury: the sensitivity of the diabetic heart to ischemic injury is decreased. Cardiovasc Res 1997, 34:113-120.

26. Miki T, Itoh T, Sunaga D, Miura T: Effects of diabetes on myocardial infarct size and cardioprotection by preconditioning and postconditioning. Cardiovasc Diabetol 2012, 11:67.

27. Van der Mieren G, Nevelsteen I, Vanderper A, Oosterlinck W, Flameng W, Herijgers P: Angiotensin-converting enzyme inhibition and food restriction in diabetic mice do not correct the increased sensitivity for ischemia-reperfusion injury. Cardiovasc Diabetol 2012, 11:89.

28. Kersten JR, Toller WG, Gross ER, Pagel PS, Warltier DC: Diabetes abolishes ischemic preconditioning: role of glucose, insulin, and osmolality. Am J Physiol Heart Circ Physiol 2000, 278:H1218-H1224

29. del Valle HF, Lascano EC, Negroni JA, Crottogini AJ: Absence of ischemic preconditioning protection in diabetic sheep hearts: role of sarcolemmal KATP channel dysfunction. Mol Cell Biochem 2003, 249:21-30.

30. Kersten JR, Schmeling TJ, Orth KG, Pagel PS, Warltier DC: Acute hyperglycemia abolishes ischemic preconditioning in vivo. Am J Physiol 1998, 275:H721-H725.

31. Tsang A, Hausenloy DJ, Mocanu MM, Carr RD, Yellon DM: Preconditioning the diabetic heart: the importance of Akt phosphorylation. Diabetes 2005, 54:2360-2364

32. Ghosh S, Standen NB, Galinianes M: Failure to precondition pathological human myocardium. J Am Coll Cardiol 2001, 37:711-718.

33. Hassouna A, Loubani M, Matata BM, Fowler A, Standen NB, Galinanes M: Mitochondrial dysfunction as the cause of the failure to precondition the diabetic human myocardium. Cardiovasc Res 2006, 69:450-458.

34. Sivaraman V, Hausenloy DJ, Wynne AM, Yellon DM: Preconditioning the diabetic human myocardium. J Cell Mol Med 2010, 14:1740-1746.

35. Jonassen AK, Brar BK, Mjos OD, Sack MN, Latchman DS, Yellon DM: Insulin administered at reoxygenation exerts a cardioprotective effect in myocytes by a possible anti-apoptotic mechanism. J Mol Cell Cardio 2000, 32:757-764.

36. Melin J, Hellberg O, Larsson E, Zezina L, Fellstrom BC: Protective effect of insulin on ischemic renal injury in diabetes mellitus. Kidney Int 2002, 61:1383-1392.

37. Sack MN, Yellon DM: Insulin therapy as an adjunct to reperfusion after acute coronary ischemia: a proposed direct myocardial cell survival effect independent of metabolic modulation. J Am Coll Cardiol 2003, 41:1404-1407

38. Kersten JR, Montgomery MW, Ghassemi T, Gross ER, Toller WG, Pagel PS, Warltier DC: Diabetes and hyperglycemia impair activation of mitochondrial K(ATP) channels. Am J Physiol Heart Circ Physiol 2001, 280: H1744-H1750

39. Ishihara M, Inoue I, Kawagoe T, Shimatani Y, Kurisu S, Nishioka K, Umemura T, Nakamura S, Yoshida M: Effect of acute hyperglycemia on the ischemic preconditioning effect of prodromal angina pectoris in patients with a first anterior wall acute myocardial infarction. Am J Cardiol 2003, 92:288-291.

40. Wade $\mathrm{AO}$, Cordingley JJ: Glycaemic control in critically ill patients with cardiovascular disease. Curr Opin Crit Care 2006, 12:437-443.

\section{doi:10.1186/1475-2840-11-124}

Cite this article as: Engbersen et al:: Improved resistance to ischemia and reperfusion, but impaired protection by ischemic preconditioning in patients with type 1 diabetes mellitus: a pilot study. Cardiovascular Diabetology 2012 11:124.

\section{Submit your next manuscript to BioMed Central and take full advantage of:}

- Convenient online submission

- Thorough peer review

- No space constraints or color figure charges

- Immediate publication on acceptance

- Inclusion in PubMed, CAS, Scopus and Google Scholar

- Research which is freely available for redistribution 